\title{
Chapter 7 \\ Interview: Creating Knowledge \\ Collaboratively to Forge a Richer Society \\ Tomorrow-An Innovation Ecosystem \\ to Spearhead Social Transformation
}

\begin{abstract}
As social problems at home and abroad grow increasingly complex and diverse, the Government of Japan is pursuing its vision of Society 5.0, the supersmart society that balances economic advancement with the resolution of social problems and where all can live comfortable lives. Meanwhile, the UN has advocated Sustainable Development Goals (SDGs) to address global challenges and has called upon industry to contribute to SDGs through business activities.

How can the R\&D efforts of universities and businesses spark innovation and accelerate the pace of social transformation? This question was discussed in the following dialog between the University of Tokyo's Makoto Gonokami and Hitachi's Hiroaki Nakanishi, both members of the Growth Strategy Council.
\end{abstract}

Keywords Public-private-academia collaboration · Innovation ecosystem · IoT-led digital revolution $\cdot$ SDGs $\cdot$ Social transformation

As social problems at home and abroad grow increasingly complex and diverse, the Government of Japan is pursuing its vision of Society 5.0, the supersmart society that balances economic advancement with the resolution of social problems and where all can live comfortable lives. Meanwhile, the UN has advocated Sustainable Development Goals (SDGs) to address global challenges and has called upon industry to contribute to SDGs through business activities.

How can the R\&D efforts of universities and businesses spark innovation and accelerate the pace of social transformation? This question was discussed in the following dialog between the University of Tokyo's Makoto Gonokami and Hitachi's Hiroaki Nakanishi, both members of the Growth Strategy Council.

\footnotetext{
The original version of this chapter was revised: This book was inadvertently published with the incorrect license type CC BY 4.0 and the Open Access License has been amended throughout the book to the correct license type CC-BY-NC-ND. The correction to this chapter is available at https://doi.org/10.1007/978-981-15-2989-4_9
} 


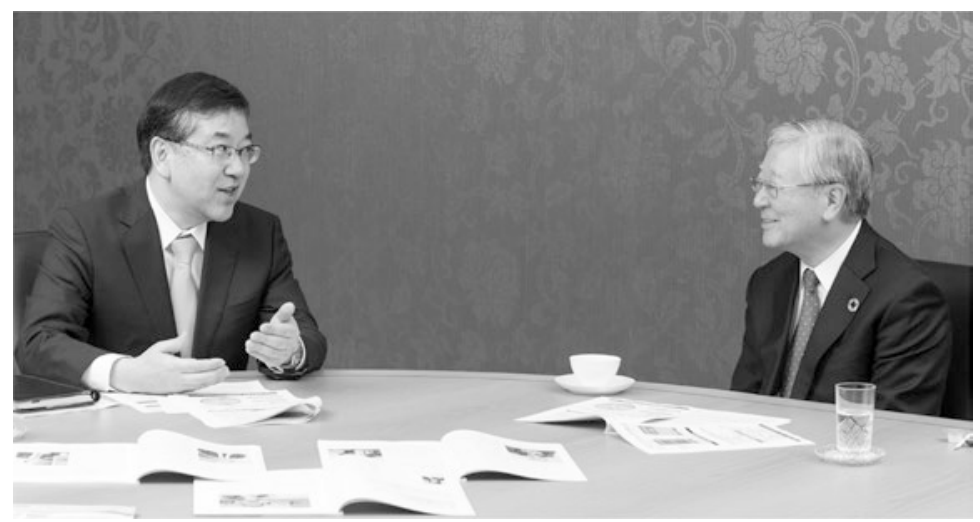

Makoto Gonokami, President of the University of Tokyo (left). Hiroaki Nakanishi, Chairman of Hitachi (right).

\subsection{Society 5.0 Is About a Common Goal}

Nakanishi Society today faces a myriad of problems, and there is a growing impetus for the social reforms necessary to address these problems. This situation was reflected in the 5th Science and Technology Basic Plan, approved by the Cabinet on January 22, 2016. Under the major theme of "future industry and social transformation," the Plan outlined a firm commitment to "Society 5.0," a vision that calls for more effective R\&D so as to stimulate disruptive innovation, and that calls on Japan to lead the world in implementing a supersmart society. You and I were involved in drafting this plan as members of the Council for Science, Technology, and Innovation. May I ask you first of all just to recap how you define Society 5.0 and what you see as the context behind it?

Gonokami The time when we drafted the 5th Science and Technology Basic Plan was a time of mounting expectations for an IoT-led digital revolution. After reflecting on the outcomes of the 4th Basic Plan, we decided that "Society 5.0" should be a key term to encapsulate our future vision, in that it expresses the idea of taking society as a whole to a new place.

You and I then worked to flesh out ideas on Society 5.0 as members of the Growth Strategy Council, which had been established in the Headquarters for Japan's Economic Revitalization in September 2016. We soon realized that a digital revolution would involve a disruptive transformation of all industrial and social systems. This phenomenon could be called super-smartification-a situation where the use of Big Data and other new value-generating processes lead to seismic changes in the very fabric of society. 
We recognized that we should not sit back and watch as technology reshapes society. Instead, we should actively seize the opportunity and lead the process. Social transformation is an urgent task. This is particularly true in the case of the shrinking and aging population, a problem that we must address within the space of a few years. We saw this situation as an opportunity for action. We knew that we could only overcome the problem through a game-changing solution. To this end, we would need to develop necessary technologies and services ahead of the rest of the world and highlight the tasks to tackle. We thus took stock of Japan's existing social values and its strengths and then discussed the implications of social transformation-what shape will society be in following the transformation, and what should we be doing now? We decided that the term "Society 5.0" would help focus minds in this direction. It was thanks in large part to you that the term caught on.

Nakanishi You give me too much credit. For my part, I understood how important the concept was thanks to my experience in Hitachi. As part of a group-wide reform project, I had introduced a social innovation business, a business that focuses on taking society in a new direction. Initially, many people in my company were skeptical, saying that they were unsure what social innovation was all about. Even so, I made a point of using the term, as I believed we needed a concept to indicate an overall direction and vision-something you cannot do if you only ever talk about specific technologies.

The same goes for Society 5.0. The concept allows us to share a common goal, to create a new society together. We use the term "supersmart society" because we set our sights beyond a technologically driven society, to a more human-oriented society. In designing the architecture for such a society, we should not dictate from the outset what Society 5.0 should look like. As we develop the concept, we must give room for creative and innovative ideas to grow and allow new values to emerge.

Gonokami You just reminded me of something. Around 2 years before I became president of the University of Tokyo, I established the Innovative Center for Coherent Photon Technology (ICCPT) with funding from the Japan Science and Technology Agency's Center of Innovation. Coming from a background in laser physics, I wanted the ICCPT to spark a manufacturing revolution by integrating laser optics with materials technology. To that end, the ICCPT would work with other research institutes and with manufacturers involved in lasers and materials processing.

During Japan's high economic growth period in the second half of the twentieth century, Japanese manufacturers succeeded in producing high-quality goods at low cost through a combination of automation and quality control. However, the proliferation of standardized, mass-produced goods has resulted in a society where people's lives are shaped by material goods. The task now is to innovate manufacturing technologies so that we shift to a society where material goods are shaped by people's lives, where manufacturers produce high-quality customized goods as cheaply as mass-produced goods. 
I believe that the digital revolution can create a sustainable society, one that uses resources efficiently according to the specific needs of individuals. The shift toward customization in manufacturing is, along with other developments such as tailormade medicine and flexibly working practices, part of a broader shift from productfocused thinking to individual needs-focused thinking, and it is this broad shift that holds the key to social transformation. The digital revolution is not simply a matter of the tools we use; it is something that will radically transform the structure of society itself.

\subsection{Fostering the Mind-Set to Try Something New}

Nakanishi To create a digital revolution that will qualitatively transform society and create new values, we will need a new human resource development strategy.

Gonokami As I said before, we face the urgent issue of a shrinking and aging population. If we are to find a game-changing solution to this issue in the space of a few years, we need to have more minds working on it. To this end, universities need to change. It is no longer good enough just to launch young people into the workforce. Universities should invite workers to return to academia and collaborate with academics on solutions to challenges. I do not mean that more people need to return to university to restart their education. I am saying that universities should actively encourage a form of recurrent education in which adults in the workforce join forces with academics to come up with ideas on problems.

Some educators argue that children must learn programming and foreign languages from elementary school in order to prepare themselves for future changes, but this is a little unreasonable for the youth. Instead of telling the next generation, whose numbers are small, to support our generation in the years ahead, we should lead by example and take the necessary actions ourselves. We need to foster a mindset in which, instead of fearing change, one is willing to try something new and not be scared of trying something that no one else is doing.

It is people who generate new values. Therefore, universities, insofar as they educate people, have an ever-greater role to play. Universities should play a central role in driving a paradigm shift in collaboration with different sectors of society.

Nakanishi Academia has a vital role to play in reforming attitudes toward globalization. Businesses must globalize, but so too must our culture and our daily life itself. There must be a qualitative shift in our relationships with the wider world. If we engage and communicate with people of different ethnicities and cultures, we can develop the robustness to adapt to an uncertain time and a dynamically changing world. 
Gonokami The meaning of globalization is itself changing. Originally, the term suggested a homogenization process whereby developing nations adopt the models of developed nations. Nowadays, however, we understand globalization as an attempt to create a world where people from all walks of life can happily coexist. If we are to understand and respect people of different backgrounds, we must learn to see ourselves from a more proportionate perspective and in relation to others. That is why I encourage students to spend time studying overseas. For my part, I try to expand opportunities and support as many talented students as possible.

\subsection{Innovation Comes from Melting Pot of Ideas}

Nakanishi Structural change has begun in the industrial sector. The industrial boundaries are breaking down. If industries adopt global perspectives and think about things in global terms, they will be better able to plan ahead in anticipation of change. I am not saying that people in industry need to read a load of books; rather, they should learn by actually encountering and interacting with different people.

Gonokami Absolutely. People can access a vast array of information online, but that in itself will not be enough. In the years ahead, more and more value will be found in settings of flesh-and-blood encounters, such as university campuses. When people of different perspectives bring their particular experience and knowledge to the table and discuss face to face with each other, you get a melting pot of ideas from which innovation will emerge. We need to increase the opportunities for such interactions.

Nakanishi I could not agree more. We always seem to think alike! Japan's top universities also have amazing international potential. Is the University of Tokyo making efforts to globalize in some respects?

Gonokami The University of Tokyo exists to promote diversity in the world's knowledge. As such, we must clarify and communicate our values and role. If you compare the University of Tokyo to other universities around the world, you will notice that our university stands out in the fields of humanities and social sciences. This value is something that we are trying to communicate to a global audience. Integrating the humanities/social sciences, natural sciences, and technology is an essential step in creating a sustainable society that supports individuality. We are working to build new structures to facilitate interdisciplinary collaboration and transcend cross-epistemic boundaries with a view to producing globally unique value. 


\subsection{Industry-Academia-Government Collaboration for Building an Innovation Ecosystem}

Nakanihsi Social and industrial structures are on the cusp of a paradigm shift not only in Japan but also around the globe. As you said at the start, to accelerate the transformation, efforts must be coordinated across sectors, and that includes academia, industry, and also the government. In June 2016, the University of Tokyo and Hitachi launched H-UTokyo Lab. to establish a shared vision and pioneer a new form of industry-academia collaboration. What do you think about this new innovation ecosystem?

Gonokami One of the most important tasks of my presidency is to enhance the foundations for industry-academia collaboration. My own research lab has so far sent over 100 students into the workforce. Around $70 \%$ of the graduates went into the industrial sector. Judging from what they have told me since then, over the past 10 years, the industries have not fully utilized these graduates' abilities. As industry undergoes structural transformation, we need to ensure that human resources are employed in positions that suit their skill set and where they can realize their full potential, so that new value can emerge. Universities can help in this task as they understand their graduates very well.

Meanwhile, industry has ever-greater expectations of academia. Amid the toughening global competition and the need for quick results, businesses must keenly discern where to apply their strengths and what to invest in. Academics are good at taking a longer term view of things, a skill they gain in their fields of study. To deploy these long-term insights, we need a new form of industry-academia collaboration, one that takes into account the changes in the business environment. The first step is to establish the contractual structures that will enable businesses to invest in universities with peace of mind. We are already seeing results in this area, and so I look forward to seeing an innovation ecosystem develop in the years ahead.

Nakanihsi Yes indeed, the business climate is growing more complex, and in many cases, it is hard to see what the real issues are. Against this backdrop, businesses will not find solutions if they rely only on their own theories and hypothetical scenarios.

That is why there must be a broader ecosystem of ideas. The collaborative model that H-UTokyo Lab. advocates is one in which the top businesses and universities engage with each other, not only in technological projects, but also in sharing a common future vision and finding real-life applications for the university's diverse knowledge so as to forge shortcuts to solutions. Government should engage in the process too, as the future vision concerns social problems. Venture capitalists also have an essential role to play when it comes to financing. A paradigm shift and new industrial creation will be possible once the stage is set for these four actors to work together, with academic knowledge as the driving force. Having lagged behind its overseas counterparts in this respect, Japanese industry is now waking up to the 
need for such collaboration. So I feel we now have a great chance to promote a new homegrown model of an innovation ecosystem underpinned by industry-academiagovernment collaboration.

Gonokami As you said, venture capital has a vital role to play. In 2004, our university founded a venture capital firm called the University of Tokyo Edge Capital (UTEC). UTEC has supported the commercial application of research findings and worked to build up a body of knowledge necessary for such. Although we still have some way to go to catch up with the top US universities, we have helped form around 300 startups, 17 of which are now listed companies. The aggregate market value is 1.4 trillion yen. I anticipate that industrial sector will increasingly support the commercialization of research findings through carve-out startups, so I am sure that industry-academia collaboration will be possible by sharing our expertise in launching startups.

Nakanishi In 2015, you released "The University of Tokyo: Vision 2020." The basic principle underlying this vision is "Synergy Between Excellence and Diversity: Acting as a Global Base for Knowledge Collaboration." Would you say that this principle is the same idea as the innovation ecosystem?

Gonokami Having led East Asia in terms of academic and industrial innovation, Japan is an ideal place for creating new knowledge with cross-border value, and I want the University of Tokyo to be a base for such knowledge creation. In an ecosystem that produces knowledge with direct economic value, Japan will always have a role to play.

Nakanishi I want H-UTokyo Lab. to bring industry-academia collaboration into a new phase and promote an ecosystem that engenders innovation. Energy is one of the areas in which we are pursuing research. This field involves numerous stakeholders and the goal of the research is not to benefit Hitachi alone. In this respect, I believe we can form an ecosystem core.

Gonokami The need to find a game-changing solution is a matter of urgency, so we must press ahead with the task of finding some practical application for our research findings.

\subsection{Linking Research Activities to SDGs}

Nakanihsi So far, we have discussed Society 5.0 as a national vision, but as industry, academia, and government work to produce new values, I believe they should be guided by the worldwide future vision contained in the UN's SDGs. You wasted no time in incorporating the SDGs into the university's business strategy. What do you see as the role of leaders in contributing to the SDGs? 
Gonokami Earlier, I mentioned our Vision 2020, which outlines the aim of creating synergy between excellence and diversity. Under this aim, we have sought to produce excellence from diverse activity. In other words, we have encouraged researchers and students to act based on their free ideas, believing that a critical mass of such free agency will provide a driving force to move society toward a better direction. We understood that we can only achieve this goal if the researchers and students are committed to a common vision at higher levels. It just so happened that the UN announced its SDGs around this time (in 2015), and so we decided to set the SDGs as our goals. When we announced these SDG-inspired goals, it made little impact at first, but attention picked up as more people realized how important SDGs are in attracting active investment and enlivening the economy.

You were part of this trend too; didn't Keidanren update Charter for Good Corporate Behavior and Implementation Guidance to incorporate the SDGs? Coupled with the global rise in ESG funding, SDGs are encouraging businesses to step up their efforts in promoting sustainable corporate value.

At the University of Tokyo, we started with getting the teaching staff to record which of the 17 SDGs correspond to their teaching or research activities so that we could map out these activities. Over 150 activities were recorded. Our activity map helped us visualize the areas where our university is doing well. It also allowed to identify interlinked research projects, where we could encourage interdisciplinary research.

SDGs are indispensable in that they drive economic activity while also fostering a more accommodating form of capitalist economic development. It is in this that their value lies. Universities have a role to play in adeptly matching up SDGs with research activities so as to derive solutions to the challenges.

Nakanishi This overlaps with what you just said, but I think the reason SDGs have gained solid traction is because more people are adopting global perspectives. Businesses have traditionally had the notion that as they earn profits by imposing a burden on the environment, they can make an environmental contribution in return. However, as the idea that the whole world is connected has permeated deep into society, this traditional approach is not producing value anymore. Businesses need to go back to basics in a sense. They need to share common goals and plan environmentally sound business activities with global perspectives from the outset so as to achieve sustainability in the true sense.

Thanks to SDGs, business leaders are increasingly realizing that challenges related to the environment and energy are related at a fundamental level to the problem of poverty. In this respect, the role of leaders in the industrial sector is to restructure business.

Gonokami A notable feature of university research is the diverse range of timescales. Some research projects are very short-term, but there are also some projects that a university can sustain over a 100-year or even a 200 -year time span. Industry, too, once operated with long-term perspectives, but economic cycles have become shorter, making it hard for businesses to sustain long-term research and business 
projects. SDGs may help reverse this trend. If industry and academia back each other up, they may create an environment in which businesses can pursue projects that have a greater range of timescales, including longer term projects, with peace of mind while retaining economic rationality.

Nakanihsi So you are saying that long-term projects should not just be left to the universities but conducted jointly.

This year (2018), Hitachi's R\&D organization celebrated its centenary. What role do you expect corporate R\&D teams to play in the new system of industry-academia collaboration?

Gonokami Such milestones are great opportunities to take stock, and review how things are being done.

In 2017, we celebrated our 140th anniversary as a university. We looked back over our history, segmenting it into two 70-year periods, and named the ensuing third 70-year period "UTokyo 3.0." We decided that in UTokyo 3.0, we should be a university that spearheads a transformation toward a better society, a society in which individual free agency underpins the stable development of humankind as a whole.

The academic and business communities each have their own role to play. I hope that business leaders for their part will make continued efforts to pursue long-term research as part of their corporate activities. Under the vision of Society 5.0, let us work together to achieve an industrial and social transformation that attributes value not just to technology but also to the wisdom that truly serves humanity.

Nakanishi Yes, let us co-create knowledge and thereby spearhead the transformation. In 2015, we restructured our R\&D organization to make it more customer oriented. Our task at Hitachi now is to prepare our vision for the next 100 years, and you have given some valuable hints in this regard. Thank you very much for your time today.

\section{President of the University of Tokyo Makoto Gonokami, D.Sc.}

1982: Earned an M.Sc. in Physics at the Department of Physics, Faculty of Science, The University of Tokyo

1983: Research Associate, Department of Physics, Faculty of Science, The University of Tokyo 1990: Associate Professor, Faculty of Engineering, The University of Tokyo 1998: Professor, Department of Applied Physics, Faculty and Graduate School of

Engineering, The University of Tokyo

2010: Professor, Department of Physics, Faculty of Science and Graduate School of Science, The University of Tokyo

2012: Vice President of the University of Tokyo

2014: Dean of the Faculty of Science and Graduate School of Science, The University of Tokyo

2015: President of the University of Tokyo 
Chairman and Representative Executive Officer of Hitachi, Ltd. Hiroaki Nakanishi

1970: Joined Hitachi, Ltd.

2003: General Manager of Global Business, Vice President, and Executive Officer, Hitachi, Ltd.

2004: Senior Vice President and Executive Officer, Hitachi, Ltd.

2005: Chairman and CEO, Hitachi Global Storage Technologies Inc.

2006: Executive Vice President and Executive Officer, Hitachi Ltd.

2010: Representative Executive Officer and President, Hitachi Ltd.

2014: Representative Executive Officer, Chairman and CEO, and Director, Hitachi Ltd.

2016: Executive Chairman and Representative Executive Officer, Hitachi Ltd.

*The above is an extract from "Innovators," a special edition (March 2018) of Hitachi Review to commemorate the centenary of Hitachi's R\&D Division.

Open Access This chapter is licensed under the terms of the Creative Commons AttributionNonCommercial-NoDerivatives 4.0 International License (http://creativecommons.org/licenses/ by-nc-nd/4.0/), which permits any noncommercial use, sharing, distribution and reproduction in any medium or format, as long as you give appropriate credit to the original author(s) and the source, provide a link to the Creative Commons license and indicate if you modified the licensed material. You do not have permission under this license to share adapted material derived from this chapter or parts of it.

The images or other third party material in this chapter are included in the chapter's Creative Commons license, unless indicated otherwise in a credit line to the material. If material is not included in the chapter's Creative Commons license and your intended use is not permitted by statutory regulation or exceeds the permitted use, you will need to obtain permission directly from the copyright holder. 